\title{
3d modeling and fem analysis for solar panel mounting system on a house roof
}

\author{
Cornel Cătălin Gavrilă ${ }^{1 *}$, Radu Velicu $^{2}$, Mihai -Tiberiu Lateş $^{3}$ \\ ${ }^{1}$ Transilvania University of Brasov, cgavrila@unitbv.ro, Romania \\ ${ }^{2}$ Transilvania University of Brasov, rvelicu@unitbv.ro, Romania \\ ${ }^{3}$ Transilvania University of Brasov, latesmt@unitbv.ro, Romania
}

\begin{abstract}
Mechanical structures 3D modeling in the aim of real-time simulation of the product dynamic behavior, using computer performing software, is a necessity. In the paper, there are presented some aspects regarding the 3D modeling and FEM analysis for a mounting system used to fix solar panels or collectors on house roof. First, there are presented some general aspects of the mounting systems used to fix solar panels on the house roof. Then there are presented the aspects of virtual modeling of these parts, using CATIA software. Then, there are presented some aspects of the Finite Element Analysis and the results of this. In the final part of the paper, there are presented the conclusion.
\end{abstract}

\section{Introduction}

$\mathrm{T}$ HE paper presents some aspects regarding the virtual modeling and FEM analysis for a mounting system used to fix solar panels (or collectors) on house roof. Generally, for the solar panels or collectors, the producers are also providing the adequate fixing kit, Innoterm Katalog [1]. Mainly, the solutions refer more to the solar panels used than the roof surface used for it. However, an increased number of solar panels are placed to be used on classic house roofs, previously manufactured by ceramic tiles. For these old roofs types, the kits provided are not matching very well. This mismatching lead usually to the new tiles is breaking and rainfall water drip inside the construction.

The ceramic tiles produced and used in Romania are standardized according to SR EN $1304+$ A1: 2001 [2] (the former Romanian STAS 515 - Ceramic Tiles and Ridges). According to the standard, the tiles can be in a big format, with drains and shafts, or in smaller standard format, type "sawtooth" or "scales". The scales tiles type main dimensional characteristics are presented in Fig. 1. It can be observed that the tiles can be produced with one nose, as in Fig. 1, a, or with two nose, as in Fig. 1, b.

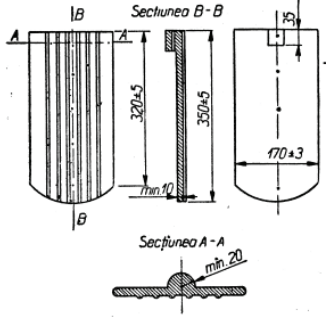

a.

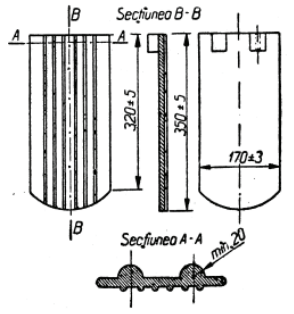

b.
Fig. 1. The scale tiles.

Usually, the tiles are arranged in the network (Fig. 2) or line, on the roof structure made of thin wide woods placed on wood timbers. For scale tiles, in a network arranged, the wide woods distance is $160 \mathrm{~mm}$ Tondach Catalogue [3].

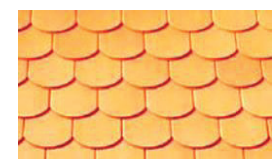

Fig. 2. The scale tiles in a network arrangement.

One particular aspect for tile roofs can be observed in section (Fig. 3). Because of rows tiles superposition, the declination of tile, given by the angle $\alpha_{t}$, differs by the general roof declination, provided by the angle $\alpha_{r}$. If the manufacturing of the roof is well done, all tiles should have the same declination.

\footnotetext{
*Corresponding author: cgavrila@unitbv.ro
} 


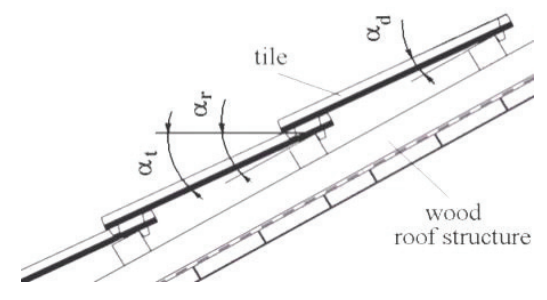

Fig. 3. The tiles and roof declination.

The difference between the declinations of roof and tile is given by relation

$$
\alpha_{\mathbf{d}}=\alpha_{\mathbf{r}}-\alpha_{\mathbf{t}} \cdot(1)
$$

The angle $\alpha_{d}=2 \ldots 7$ degrees, and may vary depending on the tile dimensions, shape or misalignments and also by wood roof structure Tondach Catalogue [3]. Because of these, the contact surface between each tile and wood wide is reduced, at the limit, to a contact line under the tile nose. Usually, to prevent the rainfall water drip inside the construction, the fixing solutions to place different installations on the roof, consist of metal clips inserted between the tiles and fixed on roof wood structure. An example of solar panel fixing solution, offered by the producer, is presented in Fig. 4, a, and b Innoterm Katalog [1].

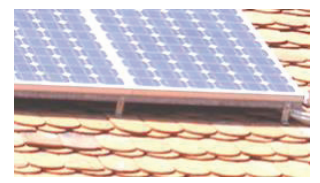

a.

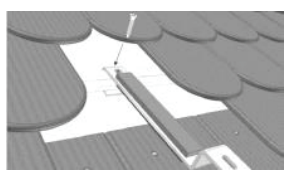

b.
Fig. 4. An example of solar panel fixing solution.

As it was presented, any object inserted between tiles should change the declination of the tiles placed above. If the metallic clip width, the above tiles declination changes and, as a consequence, the fit with other tiles and roof elements is worst and lead to premature tiles breaking in subjected area.

\section{The 3D modeling}

The virtual model is developed, using CATIA software, for the metallic clip and the ceramic tile as the main parts involved in solar panel fixing operation on the roof $\mathrm{C}$. Alexandru [4] and I. G. Ghionea[5]. The wood roof structure, which serves to support the entire assembly, is considered as rigid.

For the metallic clip, the first step is to sketch the main section. To fit the clip in the roof structure, the main dimension is corresponding to this, especially the difference between the declinations, $\alpha_{d}=2$ degrees, for scale tiles. Also, the clip width is $25 \mathrm{~mm}$. Then, using
Part Design module, the virtual model is completed, as is presented in Fig. 5.

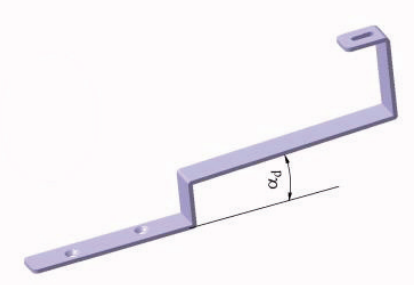

Fig. 5. The metallic clip virtual model

For scale tile, the first step is to sketch the main section. Because there is two type of tiles, with one nose and with two noses, the virtual model are made for both types. Then, using Part Design module, the virtual models are completed, as is presented in Fig. 6, a, for one nose tile, respectively, in Fig. 6, b, for two nose tile.

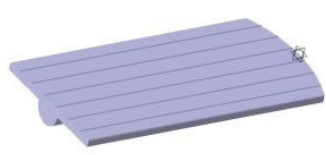

a.

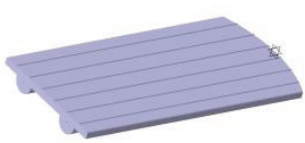

b.
Fig. 6. The scale tiles virtual models

\section{The Finite Element Analysis}

For analysis, the previous models for the metallic clip and also for the tiles will be used. The material properties, as Young modulus, Poisson coefficient, Tensile Yield Strength, Ultimate Strength should be defined.

For the metallic clip, the material is steel R. Velicu [6]. For the analysis, the loading force for metallic clip depends on solar panel weight, including the frame and fixing kit and also the wet snow weight. The considered snow layer is $150 \mathrm{~mm}$ Technical regulation CR 1-1$3 / 2012$ [7], and the snow mass which covers a solar panel, dimension 1650 x $990 \mathrm{~mm}$, is $64 \mathrm{~kg}$. Taking account that the clip number is 6 , results in the loading force on one clip, $F=291 \mathrm{~N}$. The force is applied vertically on the clip, corresponding to a tile declined at 30 degrees by horizontal reference. For simulation, the metallic clip is considered fixed on the surface fixed on timber wood. To estimate the deformations, the metallic clip will be also considered with no tile above. The model needs to mesh into finite elements, solids and deformable, type hexahedral and tetrahedral, with integration node M. T. Lateş, R. Velicu, and R. Papuc [8]. The metallic clip model, with a defined force, is presented in Fig. 7.

\footnotetext{
*Corresponding author: cgavrila@unitbv.ro
} 


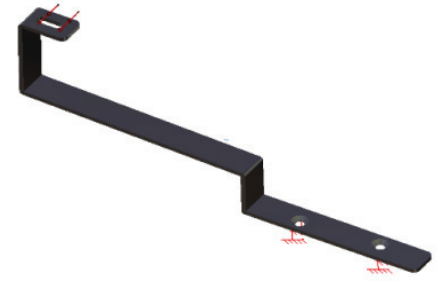

Fig. 7. The metallic clip model with defined force

For the scale tiles, the material is ceramic, with the main properties given by C. Bob, and P. Velicu [9] and I. Teoreanu, N. Ciocea, A. Bărbulescu and N. Ciontea, [10]. The ceramic materials are fragile - under the load, are subjected to break before some elastic deformations. Also, the ceramic materials present the static fatigue - for an increased time of load application, the break resistance is decreasing. For analyze, the ceramic material for tiles is considered having fine texture: homogeneous granulation, without material failures, as breaks or inclusions. For ceramic material, the limit stress is 15 $\mathrm{MPa}$.

Also, the model needs to mesh with finite elements, solids and deformable, type hexahedral and tetrahedral, with integration node. The tile is declined at 30 degrees by horizontal reference, and the force is the same as the metallic clip, applied on a contact surface with this. The tile is considered fixed above the nose, on the line contact and on the bottom corners, which correspond to the placing on the tiles above. The tile model with defined force is presented in Fig. 8. For results comparing, are made the models for one and two nose tiles.

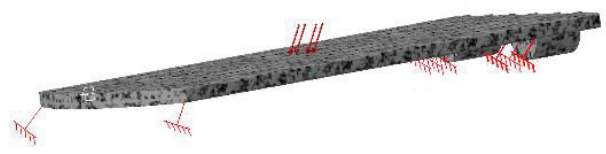

Fig. 8. The tile model with defined force

\section{Simulation and Results}

For simulation, the metallic clip is considered fixed on the surface placed on timber wood. Because of the roof manufacturing misalignments and clearances, the metal clip can be put in different positions, as it is presented in Fig. 9, a - c. The ideal positioning is presented in Fig. 10, a, where the clip is in contact with tile on the full subjected area.

In fig. 9, b, is presented a real positioning, where the contact without loading appear at the top of the tile and the folding corner of the clip. When loading, the contact surface increase.

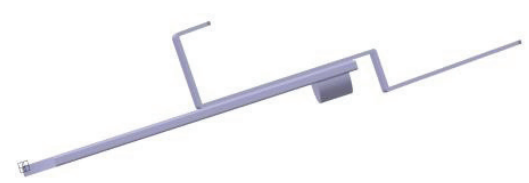

a.

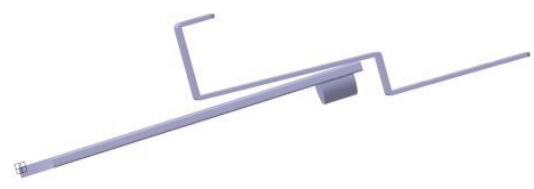

b.

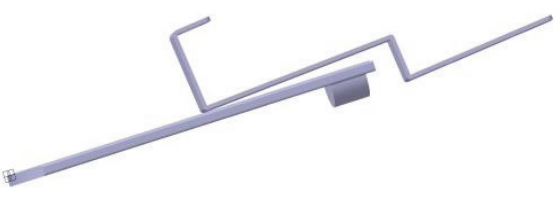

c.

Fig. 9. Positions between the metallic clip and tile

Another real positioning is presented in fig. 9, c, where the contact surface appears between the tile surface and the above portion of the clip. In this case, when loading, the contact remains reduced to a small area.

To estimate the metallic clip deformations, there will be considered with no contact with the tile above, corresponding to the situation from Fig. 9, b.

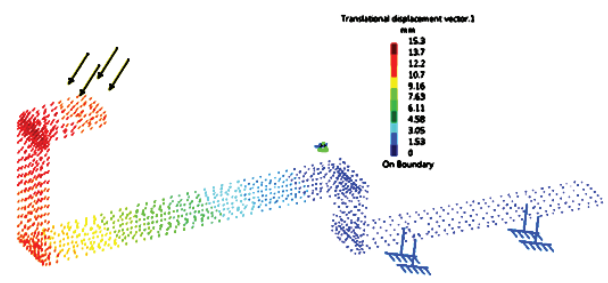

Fig. 10. Metallic clip model with deformation values

In Fig. 10 there are presented the deformations, and it can be observed that the maximum deformation value appear in the in the solar panel assembling area and exceed $15 \mathrm{~mm}$. Under the load, the metallic clip deformation increase just until its bottom end is touching the tile surface, depending on the misalignment size. Then, the load is also taken by tile.

In Fig. 11 is presented the stress on the metallic clip; the maximum value is $491 \mathrm{MPa}$ and appears in the middle zone, where the clip is folded.

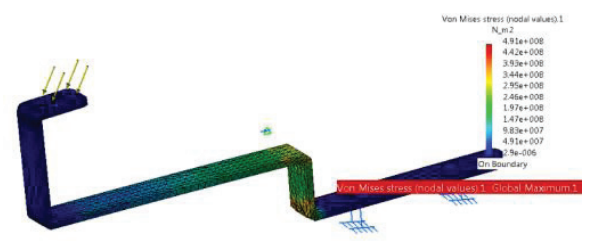

Fig. 11. Metallic clip model with stress values

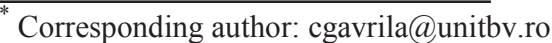


For the tile simulation, are considered the both models, with one and also with two noses. The load on the tile is applied distributed on the contact area with the bottom end of the metallic clip. Because the contact area may vary, depending on the tile and clip folding radius and also by positioning on the roof structure, there are considered few cases of contact surfaces. Because the tiles are subjected to break before some elastic deformations, only the stress values are presented.

The first situation is when the tile contact area with clip is reduced to $25 \times 5 \mathrm{~mm}$, which corresponds to increased misalignments and increased clip deformations.

The obtained stress maximum values are $20,9 \mathrm{MPa}$ for one nose tile (fig. 12, a), and, respectively 25,2 MPa for two nose tile (fig. 12, b). It can be observed that the maximum value appears, for both tile models, at contact area with clip; the value exceed the recommended stress value So, the tile break is in the contact area (tile is breaking in two parts).
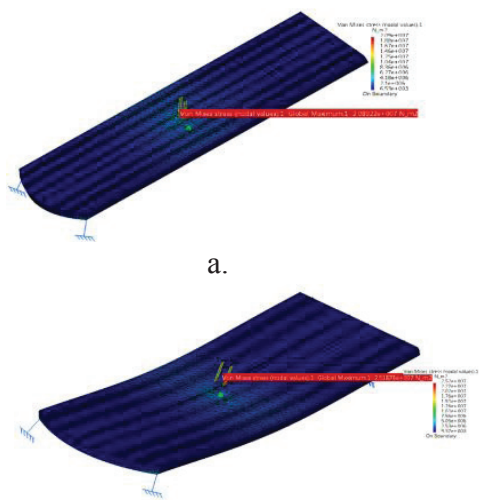

b.

Fig. 12. Stress values on tile reduced contact area

The second situation is when the tile contact area with clip is increased to $25 \times 10 \mathrm{~mm}$, which correspond to reduced misalignments and reduced clip deformations.

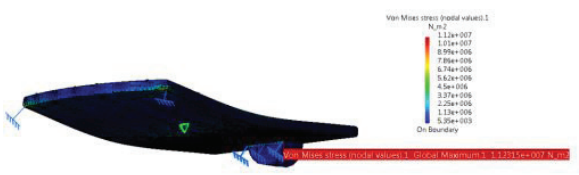

a.

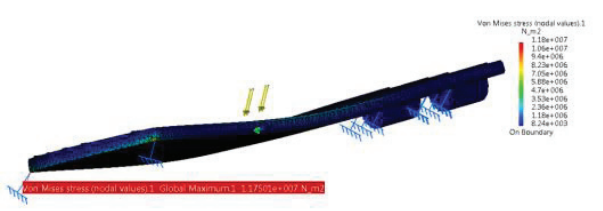

b.

Fig. 13. Stress values on tile, contact area length increased

The obtained stress maximum values are 11,2 $\mathrm{MPa}$, for one nose tile (fig. 13, a), and appears under the nose, where the tile is arranged on wide wood. For the two nose tile, the maximum value is $11,8 \mathrm{MPa}$ for (fig. 13, b) and appears on the tile above corners. So, at the one nose tile appears the possibility to break the tile nose properly. For two nose tile, appears the possibility to break its corners.

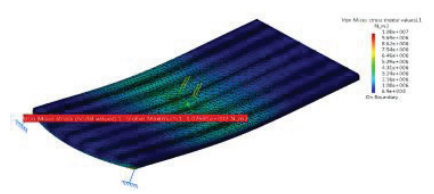

a.

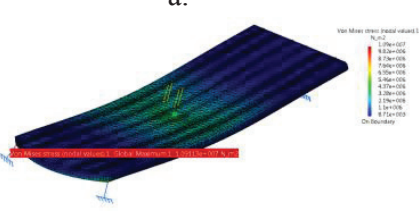

b.

Fig. 14. Stress values on tile, contact area width increased

The third situation is when the tile contact area with clip is increased by increasing the metallic clip width to $40 \mathrm{~mm}$. So, the contact surface increases to $40 \times 5 \mathrm{~mm}$.

The obtained stress maximum values are $10,8 \mathrm{MPa}$ for one nose tile (fig. 14, a), and, respectively 10,9 MPa for two nose tile (fig. 14, b). It can be observed that the maximum value appears, for both tile models, on the tile above corners. So, for both tile models, appears the possibility to break the corners.

\section{Conclusion}

On solar panels roof assembly, there are situations when, because of surfaces misalignments, the contact surface between the studied parts may be different.

For the metallic clip, the deformations and stresses values are lower than the limit values recommended in the literature for steel.

For tiles with reduced contact surface with metallic clip, appear the tile break. If the contact with metallic clip is improved, the maximal stress values are lower than the limit values recommended in the literature for the ceramic material. Taking account that the ceramic materials are fragile and present the static fatigue - for an increased time of load application, the break resistance is decreasing in subjected locations.

So, to avoid the tile breaking, the main solution is to improve the contact with the metallic clip, for example by increasing the clip width or by increasing the folding clip radius.

Also, the analysis presented lead to the conclusion that is better to use a two nose scale tile above the clip.

Similar can be created and simulated a lot of 3D models for any needed tiles and roof types. In this way, with reduced costs can be reduced the roof failures.

\section{References}

[1] Innoterm Katalog, Solar-Kollektoren, 2009 (in German).

\footnotetext{
*Corresponding author: cgavrila@unitbv.ro
} 
[2] Romanian Standard, SR EN $1304+$ A1: 2001, Ceramic Tiles and Ridges, 2001.

[3] Tondach Catalogue, Sibiu Classic Scale Tiles (Ţiglă solzi clasic Sibiu), 2008 (in romanian).

[4] C. Alexandru, Mechanical Articulated Systems Simulation on Computer (Simularea pe calculator a sistemelor mecanice articulate), Ed. Lux Libris, Brașov, 2000 (in Romanian).

[5] I.G. Ghionea, CATIA v5. Application in Mechanical Engineering (CATIA v5. Aplicații în ingineria mecanică), Editura Bren, București, 2009 (in romanian).

[6] R. Velicu, Machine Elements (Organe de Maşini), Ed. Universităti Transilvania din Brașov, 2003 (in romanian).
[7] Technical regulation CR 1-1-3/2012, Design Code: Snow Action On Construction Evaluation (Cod de proiectare. Evaluarea actiunii zapezii asupra constructiilor), 2012 (in romanian)

[8] M. T. Lateş, R. Velicu, R. Papuc, Multiscale modeling of chainguide contact by using tests and FEM. 11th World Congress on Computational Mechanics WCCM XI, Barcelona, Spain, 20-25 July 2014, pp.1062-1069.

[9] C. Bob, P. Velica, Construction Materials (Materiale de construcţii), Ed. Didactică şi Pedagogică, Bucureşti, 1978 (in romanian).

[10] I. Teoreanu, N. Ciocea, A. Bărbulescu, N. Ciontea, Ceramic and Refractory Material Technology (Tehnologia produselor ceramice şi refractare), Vol. I, Ed. Tehnică, Bucureşti (in romanian).

\footnotetext{
*Corresponding author: cgavrila@unitbv.ro
} 